\title{
First demonstration of single-mode MCF transport network with crosstalk-aware in- service optical channel control
}

Pulverer, K.; Tanaka, T.; Häbel, U.; Castro, C.; Bohn, M.; Mizuno, T.; Isoda, A.; Shibahara, K.; Inui, T.; Miyamoto, $\mathrm{Y}$.

Total number of authors:

18

Published in:

2017 European Conference on Optical Communication (ECOC)

Link to article, DOI:

10.1109/ECOC.2017.8346092

Publication date:

2017

Document Version

Peer reviewed version

Link back to DTU Orbit

Citation (APA):

Pulverer, K., Tanaka, T., Häbel, U., Castro, C., Bohn, M., Mizuno, T., Isoda, A., Shibahara, K., Inui, T., Miyamoto, Y.., Amma, Y., Aikawa, K., Jain, S., Jung, Y., Alam, S., Richardson, D. J., Nooruzzaman, M., \& Morioka, T. (2017). First demonstration of single-mode MCF transport network with crosstalk-aware in-service optical channel control. In 2017 European Conference on Optical Communication (ECOC) IEEE. https://doi.org/10.1109/ECOC.2017.8346092

\section{General rights}

Copyright and moral rights for the publications made accessible in the public portal are retained by the authors and/or other copyright owners and it is a condition of accessing publications that users recognise and abide by the legal requirements associated with these rights.

- Users may download and print one copy of any publication from the public portal for the purpose of private study or research.

- You may not further distribute the material or use it for any profit-making activity or commercial gain

- You may freely distribute the URL identifying the publication in the public portal 


\title{
First Demonstration of Single-Mode MCF Transport Network with Crosstalk-Aware In-Service Optical Channel Control
}

\author{
K. Pulverer ${ }^{(1)}$, T. Tanaka ${ }^{(2)}$, U. Häbel ${ }^{(1)}$, C. Castro(1), M. Bohn ${ }^{(1)}$, T. Mizuno $^{(2)}$, A. Isoda ${ }^{(2)}$, \\ K. Shibahara ${ }^{(2)}$, T. Inui ${ }^{(2)}, Y$. Miyamoto ${ }^{(2)}, Y$. Sasaki ${ }^{(3)}, Y$. Amma ${ }^{(3)}$, K. Aikawa ${ }^{(3)}$, S. Jain ${ }^{(4)}$, Y. Jung ${ }^{(4)}$, \\ S. Alam ${ }^{(4)}$, D. J. Richardson ${ }^{(4)}$, M. Nooruzzaman ${ }^{(5)}$, and T. Morioka ${ }^{(5)}$ \\ (1) Coriant R\&D GmbH, St. Martin Str. 76, 81541 Munich, Germany \\ (2) NTT Network Innovation Laboratories, NTT Corporation, Yokosuka, Kanagawa, 239-0847, Japan \\ (3) Advanced Technology Laboratory, Fujikura Ltd, 1440, Mutsuzaki, Sakura, Chiba, 285-8550, Japan \\ (4) Optoelectronics Research Centre, University of Southampton, Southampton, UK \\ (5) Technical University of Denmark, DK2800 Kgs. Lyngby, Denmark
}

\begin{abstract}
We demonstrate the first crosstalk-aware traffic engineering as a use case in a multicore fibre transport network. With the help of a software-defined network controller, modulation format and channel route are adaptively changed using programmable devices with XT monitors.
\end{abstract}

\section{Introduction}

In recent years, space-division multiplexing (SDM) in optical fibre transmission has become one of the hottest approaches to break the capacity limit of optical fibre ${ }^{1,2}$. Besides the attempts to demonstrate larger capacities and longer transmission distances, various network testbed experiments have now been reported ${ }^{3-6}$.

Among the various forms of SDM, singlemode MCF transport offer some specific advantages and possibilities. For example, $\mathrm{Pbit/s/fibre-class} \mathrm{capacities} \mathrm{and} \mathrm{low-power}$ optical transport networks are feasible using dense-SDM (DSDM) with a spatial multiplicity over $30^{7,8}$. In addition, the long-haul digital coherent transmission employed today over conventional single-mode fibre (SMF) can be fully supported using appropriate crosstalk (XT) management ${ }^{9}$. However, no testbed demonstrations have been reported so far that simultaneously satisfy these two advantages.

In this paper, we present the first single-mode MCF transport network using XT-aware and programmable optical channels with $\mathrm{XT}$ monitoring. In the testbed, we demonstrate a traffic engineering use case, in which optical channels are adaptively (re)configured subject to consideration of inter-core XT with the help of an software-defined network (SDN) controller.

Single-mode multicore fibre (MCF) transport network with XT-aware optical channel control

As transmission distances become longer in MCF transport networks, inter-core XT becomes a limiting factor - especially for optical channels using higher order modulation formats. In addition, the XT impairment will change in time in response to changes in optical channel assignment in adjacent cores. Therefore, the consideration of $\mathrm{XT}$ is indispensable to realise the full potential of MCF transport networks.

Figure 1(a) shows our proposed XT-aware single mode MCF transport network architecture. In the data-plane, three reconfigurable optical add/drop multiplexers (ROADMs) are connected with three SMF/MCF links which include inline amplifiers. In particular, the MCF links contain fan-in/fan-out (FI/FO) devices, and inter-core XT monitors to estimate the $\mathrm{XT}$ value for the link. The transponders have the capability of adaptively selecting between quadrature phase shift keying (QPSK), 8 quadrature amplitude modulation (8QAM), and 16QAM formats. An optical channel between ROADM 1 and 3 traverses either a MCF link (Link $A$ ) or mixed MCF and SMF links (Link B-C).

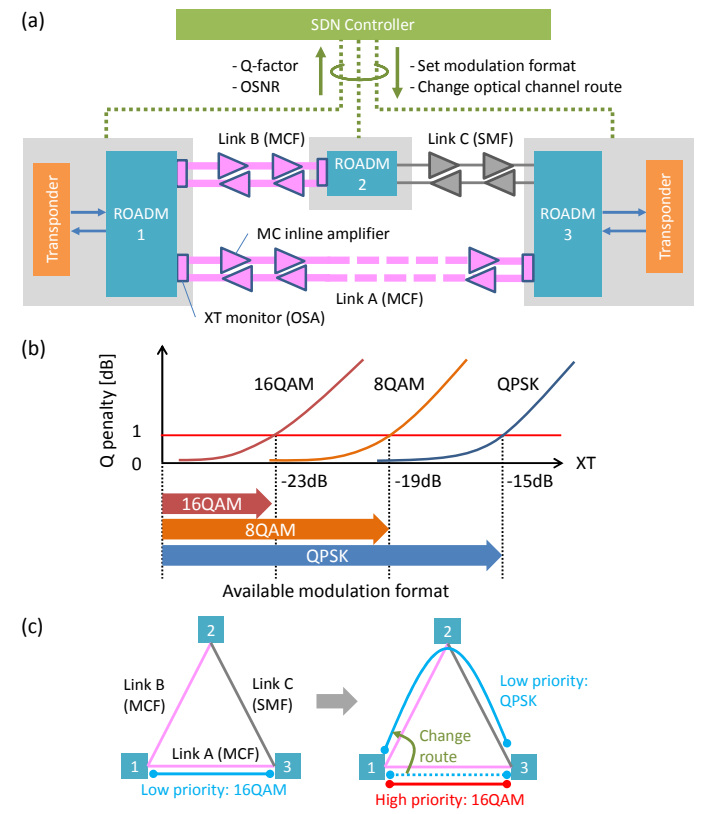

Fig. 1: (a) Architecture of the single mode MCF transport network with XT-awareness, (b) available modulation formats with respect to $\mathrm{XT}$, and (c) use case of XT-aware traffic engineering. 


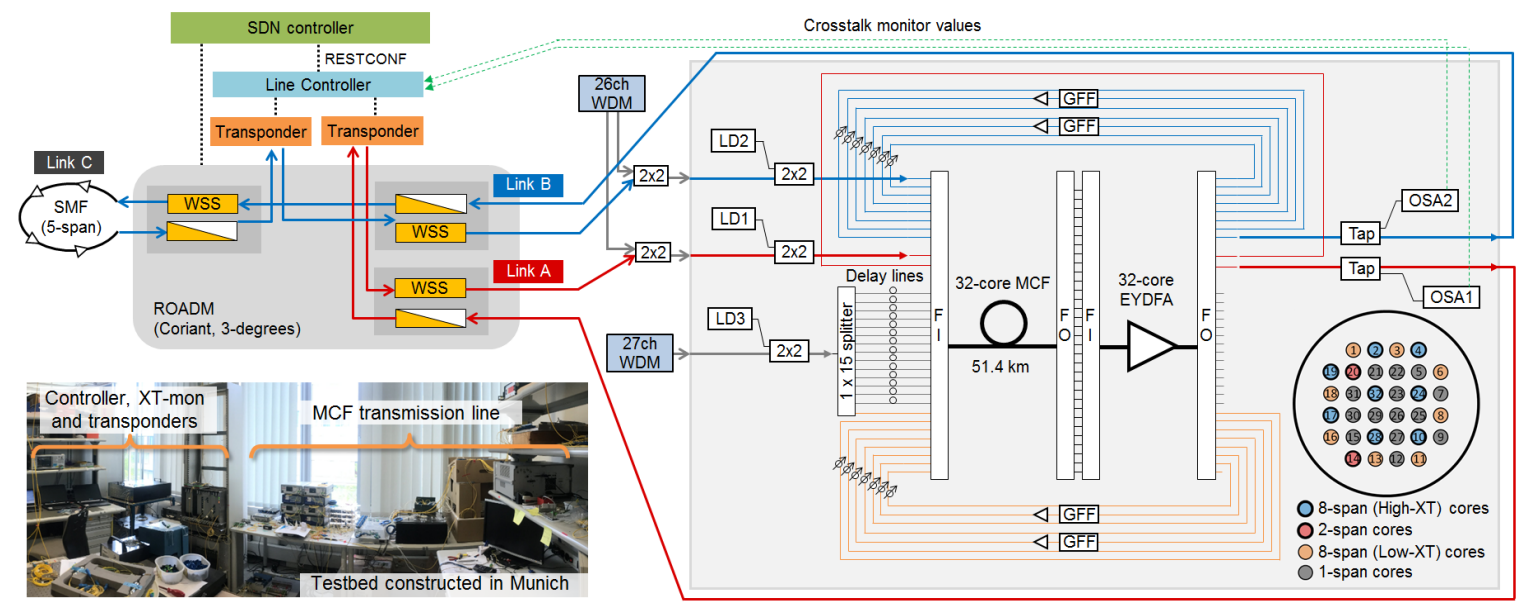

Fig. 2: Experimental setup.

In the control plane, an OpenDaylight-based SDN controller manages resource abstraction within the transport network context and provides the interface for northbound service management. The SDN controller collects intercore XT and optical signal-to-noise ratio (OSNR) values at regular intervals from each node. Based on the monitored values, the SDN controller sets the transponders to an appropriate modulation format or configures the ROADMs to change optical channel routes.

When the XT of a link is estimated in the above scheme, a suitable modulation format can be determined from not only the OSNR of the total link but also the XT induced in the MCF link. If the allowable $Q$ penalty due to crosstalk is $<1$ $\mathrm{dB}$ under the relationship between $\mathrm{Q}$ penalty and $\mathrm{XT}$, the $\mathrm{XT}$ requirement for $16 \mathrm{QAM}, 8 \mathrm{BAM}$, and QPSK is $<-23 \mathrm{~dB},<-19 \mathrm{~dB}$, and $<-15 \mathrm{~dB}$, respectively (Fig. 1(b)).

The testbed demonstrates the traffic engineering shown in Fig. 1(c) as a representative use case where XT-awareness is of importance. The node and link numbers indicated in the figure correspond to those in Fig. 1(a). First, the use case considers an established low-priority channel passing through a low-XT MCF span (Link A). Because the XT is lower than the required level, the span is capable of operating under a 16QAM format. Then, its route needs to be changed to a less favourable link (Link B-C) to make room for a newly-arrived high-priority channel. Because the XT level along the new route is high, use of 16QAM is no longer appropriate and the modulation has to be changed to QPSK or 8QAM.

\section{Testbed setup and results}

We built the experimental setup shown in Fig. 2 to demonstrate a MCF transport network with inservice XT-aware optical channel control.
The SDN controller manages two transponders and a ROADM as well as collection of transmission-line-specific parameters such as Q-factor, OSNR and XT values via the line controller. The line controller plays the role of an intermediate layer between physical and logical layers.

The test signals are generated by two programmable transponders capable of switching between 100 Gbit/s PDM-QPSK, 150 Gbit/s PDM-8QAM and $200 \mathrm{Gbit} / \mathrm{s}$ PDM-16QAM formats. These are connected via a three degree commercial ROADM. One of the directions is a configurable 400-km SMF link (5 $x 80 \mathrm{~km} / \mathrm{span})$. The other two directions are used to switch between different cores or core chains of the MCF. This allows the investigation of different deployment and operation scenarios, including $X T$ aware traffic engineering, the optimisation of signal allocation to MCF cores, and amplification power saving by concentrating traffic on MCF spans.

The transmission line consists of a $51.4-\mathrm{km}$ 32-core heterogeneous single-mode $\mathrm{MCF}^{7}$, a 32-core EYDFA ${ }^{8}$, and in-service inter-core $X T$ monitors ${ }^{9}$. To model different levels of XT impairment and their consequences in a MCF network, sets of cores were connected in series and a gain flattening filter (GFF) was inserted after every 3 spans to cover $100 \sim 400 \mathrm{~km}$ of MCF transmission distance. A set of 8 concatenated cores (cores 2, 4, 10, 17, 19, 24, 28 , and 32 ) represents a $400-\mathrm{km}$ high-XT line. A set of another 8 concatenated cores (cores 1, 3, $6,8,11,13,16$, and 18) represents a $400-\mathrm{km}$ low-XT line, and a set of 2 cores (cores 14 and 20) represent a $100-\mathrm{km}$ line where the cores were chosen to minimise $\mathrm{XT}$, using cores at the perimeter of the fibre. The remaining cores were used as single-span cores to fill up the fibre with de-correlated WDM PDM-QPSK signals (27 channels in the range $1550.918-1561.419 \mathrm{~nm}$ ). 

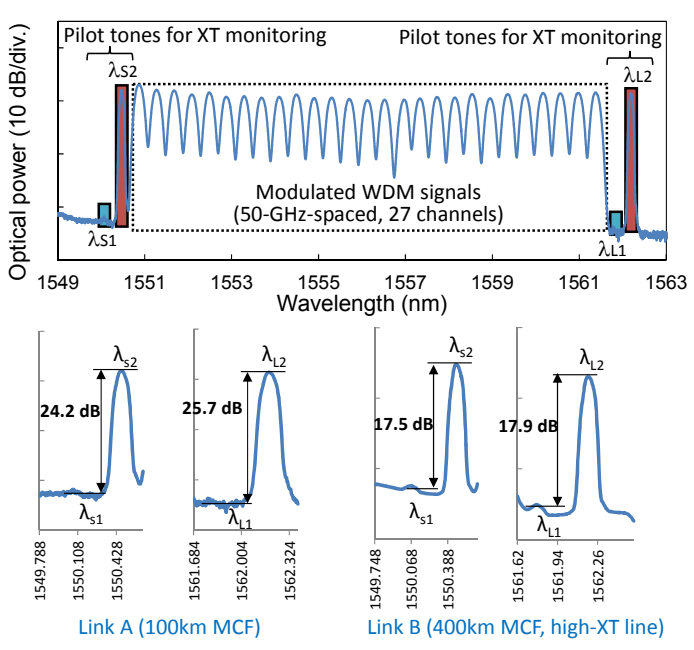

Fig. 3: XT-monitoring performance in the testbed.

Typical inter-core XT of the 400-km high-XT, 400-km low-XT, and 100-km lines were -17.4, -21.6 , and $-24.2 \mathrm{~dB}$, respectively. The 2-span $100-\mathrm{km}$ line, and the $400-\mathrm{km}$ high-XT line were used as Link $A$, and $B$, respectively.

To keep track of inter-core $\mathrm{XT}$ without disrupting traffic in the MCF, different pilot tones $\left(\lambda_{\mathrm{S} 1}=1550.116, \quad \lambda_{\mathrm{S} 2}=1550.517, \quad \lambda_{\mathrm{L} 1}=1561.826\right.$, and $\lambda_{\mathrm{L} 2}=1562.233 \mathrm{~nm}$ ) placed outside both ends of the WDM signal bandwidth were combined with the 27 channel, $50-\mathrm{GHz}$ spaced, WDM signals, and these were injected into the MCF cores. Figure 3 shows the DWDM spectrum transmitted together with the reference and $X T$ pilot tones measured using optical spectrum analysers (OSAs). The inter-core XT is estimated by comparing the optical power differences between the corresponding reference and $\mathrm{XT}$ pilot tones, and the XT value at the signal wavelength is linearly interpolated from the XT measured at WDM spectra edge.

Figure 4 shows real-time measurement data visualising a low-priority, 16QAM channel initially routed across the 2-core 100-km MCF link having low XT. It is pre-empted by a highpriority 16QAM channel and re-routed to the 8core high-XT MCF link, adaptively changing a modulation format to QPSK. After a few minutes of changed modulation format, the low priority channel was successfully switched to a new route and all the established channels showed stable error free operation after FEC decoding.

\section{Conclusions}

We have presented the concept of XT-aware optical channel configuration controlled by SDN and demonstrated $\mathrm{XT}$-aware traffic engineering in a single-mode MCF transport network testbed for the first time. The results have confirmed that both appropriate modulation format change based on $\mathrm{XT}$ monitoring and optical channel

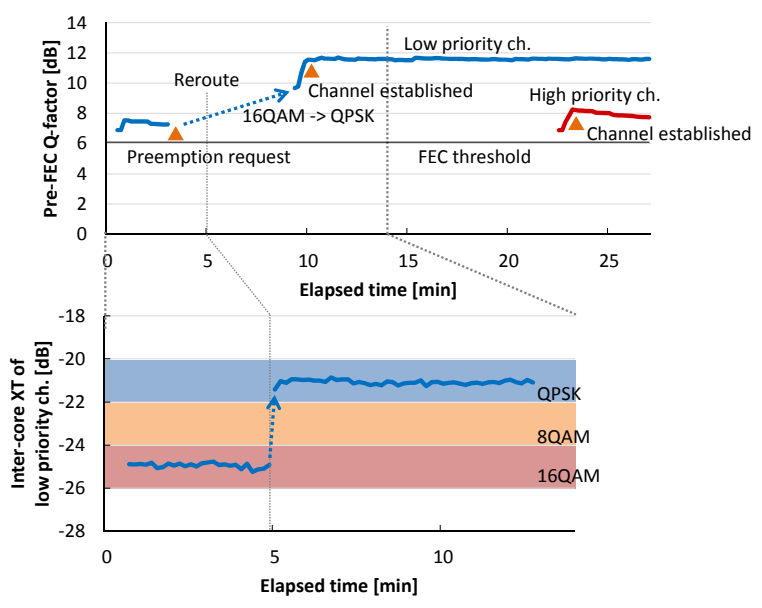

Fig. 4: Time evolution of monitored Pre-FEC Q-factor and XT values in the traffic engineering use case.

routing at ROADMs can be achieved dynamically by the SDN controller.

\section{Acknowledgements}

This work was supported by the EU-Japan coordinated R\&D project on "Scalable And Flexible optical Architecture for Reconfigurable Infrastructure (SAFARI)" commissioned by the Ministry of Internal Affairs and Communications (MIC) of Japan and EC Horizon 2020.

\section{References}

[1] D. Richardson et al., "Space-division Multiplexing in Optical Fibres," Nature Photonics, Vol. 7, p. 354 (2013).

[2] T. Morioka, "New Generation Optical Infrastructure Technologies: "EXAT Initiative" Towards 2020 and Beyond," Proc. OECC, FT4 (2009).

[3] N. Amaya et al., "First Fully-Elastic Multi-granular Network with Space/Frequency/Time Switching Using Multi-core Fibres and Programmable Optical Nodes," Proc. ECOC, PDP Th.3.D.3 (2012).

[4] V. A. J. M. Sleiffer et al., "Field Demonstration of ModeDivision Multiplexing Upgrade Scenarios on Commercial Networks," Opt. Exp., Vol. 21, no. 25, p. 31036 (2013).

[5] S. Fujii et al., "On-Demand Spectrum and Core Allocation for Reducing Crosstalk in Multicore Fibers in Elastic Optical Networks," J. Opt. Commun. Netw., Vol. 6, no. 12, p. 1059 (2014).

[6] G. M. Saridis et al., "Experimental Demonstration of a Flexible Filterless and Bidirectional SDM Optical Metro/Inter-DC Network," Proc. ECOC, M.1.F.3 (2016).

[7] T. Kobayashi et al., "1-Pb/s (32 SDM/46 WDM/768 Gb/s) C-band Dense SDM Transmission over 205.6-km of Single-mode Heterogeneous Multi-core Fiber using 96Gbaud PDM-16QAM Channels," Proc. OFC, PDP Th5B.1 (2017).

[8] S. Jain et al., "Improved Cladding-pumped 32-core Multicore Fiber Amplifier," Proc. ECOC, Th.2.D (2017).

[9] T. Mizuno et al., "In-service Crosstalk Monitoring for Dense Space Division Multiplexed Multi-core Fiber Transmission Systems," Proc. OFC, M3J.2 (2017). 